\title{
Estimating surface fluxes over the north Tibetan Plateau area with ASTER imagery
}

\author{
Weiqiang Ma ${ }^{1}$, Yaoming $\mathrm{Ma}^{1,2,3}$, Maoshan $\mathrm{Li}^{1}$, Zeyong $\mathrm{Hu}^{1}$, Lei Zhong ${ }^{2}$, Zhongbo $\mathrm{Su}^{5}$, Hirohiko Ishikawa ${ }^{4}$, and \\ Jiemin Wang ${ }^{1}$ \\ ${ }^{1}$ Laboratory for Climate Environment and Disasters of Western China, Cold and Arid Regions Environmental and \\ Engineering Research Institute, Chinese Academy of Sciences, Lanzhou-Gansu 730000, China \\ ${ }^{2}$ Institute of Tibetan Plateau Research, Chinese Academy of Sciences, Beijing, China \\ ${ }^{3}$ School of Geography and Remote Sensing, Beijing Normal University, Beijing, China \\ ${ }^{4}$ Disaster Prevention Research Institute, Kyoto University, Kyoto, Japan \\ ${ }^{5}$ International Institute for Geo-Information Science and Earth Observation, Enschede, The Netherlands
}

Received: 22 May 2008 - Published in Hydrol. Earth Syst. Sci. Discuss.: 1 July 2008

Revised: 16 December 2008 - Accepted: 16 December 2008 - Published: 26 January 2009

\begin{abstract}
Surface fluxes are important boundary conditions for climatological modeling and Asian monsoon system. The recent availability of high-resolution, multi-band imagery from the ASTER (Advanced Space-borne Thermal Emission and Reflection radiometer) sensor has enabled us to estimate surface fluxes to bridge the gap between local scale flux measurements using micrometeorological instruments and regional scale land-atmosphere exchanges of water and heat fluxes that are fundamental for the understanding of the water cycle in the Asian monsoon system. A parameterization method based on ASTER data and field observations has been proposed and tested for deriving surface albedo, surface temperature, Normalized Difference Vegetation Index (NDVI), Modified Soil Adjusted Vegetation Index (MSAVI), vegetation coverage, Leaf Area Index (LAI), net radiation flux, soil heat flux, sensible heat flux and latent heat flux over heterogeneous land surface in this paper. As a case study, the methodology was applied to the experimental area of the Coordinated Enhanced Observing Period (CEOP) AsiaAustralia Monsoon Project (CAMP) on the Tibetan Plateau (CAMP/Tibet), located at the north Tibetan Plateau. The ASTER data of 24 July 2001, 29 November 2001 and 12 March 2002 was used in this paper for the case of summer, winter and spring. To validate the proposed methodology, the ground-measured surface variables (surface albedo and
\end{abstract}

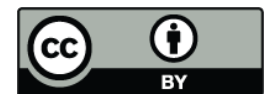

Correspondence to: Weiqiang Ma (wqma@lzb.ac.cn) surface temperature) and land surface heat fluxes (net radiation flux, soil heat flux, sensible heat flux and latent heat flux) were compared to the ASTER derived values. The results show that the derived surface variables and land surface heat fluxes in three different months over the study area are in good accordance with the land surface status. Also, the estimated land surface variables and land surface heat fluxes are in good accordance with ground measurements, and all their absolute percentage difference (APD) is less than $10 \%$ in the validation sites. It is therefore concluded that the proposed methodology is successful for the retrieval of land surface variables and land surface heat fluxes using the ASTER data and filed observation over the study area.

\section{Introduction}

The energy and water cycles play an important role in the Asian Monsoon system over the Tibetan Plateau. The Tibetan Plateau contains the world's highest elevation with average elevation about $4000 \mathrm{~m}$ relief features. It represents an extensive mass extending from subtropical to middle latitudes and is spanning over 25 degrees of longitude. Because of its topographic character, the plateau surface absorbs a large amount of solar radiation energy (much of which is redistributed by cryospheric processes), and undergoes dramatic seasonal changes of surface heat and water fluxes (e.g. Ye and Gao, 1979; Ye, 1981; Yanai et al., 1992; Ye and Wu,

Published by Copernicus Publications on behalf of the European Geosciences Union. 
1998; Ma et al., 2002a, 2006; Ma and Tsukamoto, 2002). The study on the energy exchanges between the land surface and atmosphere was also of paramount importance for the CAMP/Tibet (Ma et al., 2003a, 2005, 2006). Some interesting detailed studies concerning the land surface heat fluxes have been reported (e.g. Yang et al., 2002, 2003, 2004; Ma et al., 2002a; Choi et al., 2004; Zuo et al., 2005). These researches were, however, on point-level or a local-patch-level. Since the information of land-surface atmosphere interaction is required in this area, the aggregation of the individual results into a regional scale is necessary.

Remote sensing offers the possibility to derive regional distribution of land surface heat fluxes over heterogeneous land surface in combination with sparse field experimental stations. Remote sensing data provided by satellites are a means of obtaining consistent and frequent observations of spectral albedo and emittance of radiation at elements in a patch landscape and on a global scale (Sellers et al., 1990). The land surface variables and vegetation variables, such as surface temperature $T_{\mathrm{sfc}}$, surface hemispherical albedo $r_{0}$, NDVI, MSAVI, LAI and surface thermal emissivity $\varepsilon$ can be derived directly from satellite observations (e.g. Susskind et al., 1984; Che'din et al., 1985; Tucker, 1986; Wan and Dozier, 1989; Menenti et al., 1989; Becker and Li, 1990, 1995; Watson et al., 1990; Baret and Guyot, 1997; Price, 1992; Kahle and Alley, 1992; Li and Becker,1993; Qi et al., 1994; Norman et al., 1995; Schmugge et al., 1995; Kustas and Norman, 1997; Sobrino and Raissouni, 2000; Su, 2002; Ma et al., 2003a, b; Oku and Ishikawa, 2004; Kato, 2005). The regional heat fluxes can be determined indirectly with the aid of these land surface variables and vegetation variables (Pinker, 1990).

Studies have explored several approaches to estimate the regional distribution of surface heat fluxes in recent years. These methods require specification of the vertical temperature difference between the surface temperature and the air temperature and an exchange resistance (e.g. Kustas et al., 1989; Kustas, 1990; Wang et al., 1995; Menenti et al., 1991; Menenti and Choudhury, 1993; Bastiaanssen, 1995; Kustas and Norman, 1997; Su, 2002). However, these remote sensing retrieval methods have been performed in homogeneous moist or semiarid regions, and investigations in heterogeneous landscape of high altitudes (e.g. the Tibetan Plateau area) are rare.

NOAA/AVHRR, GMS and Landsat-7 ETM data were used to determine regional land surface heat fluxes over heterogeneous landscape of the Tibetan Plateau (Ma et al., 2003a, b, 2005, 2006; Oku et al., 2007). However, the resolution of the NOAA/AVHRR and GMS data is about $1 \mathrm{~km} \times 1 \mathrm{~km}$ and sub-pixel heterogeneity has been omitted. So does Landsat-7 ETM data. The aim of this research is to upscale in-situ point observations of land surface variables and land surface heat fluxes to the regional scale using highresolution $(15 \mathrm{~m} \times 15 \mathrm{~m})$ ASTER Data.

\section{Data and methodology}

\subsection{Data}

The intensive observation period (IOP) and long-term observation of the CAMP/Tibet have been done successfully in the past seven years. A large amount of data has been collected, which is the best data set so far for the study of energy and water cycle over the Tibetan Plateau. The experimental region, about $150 \times 250 \mathrm{~km}^{2}$, includes a variety of land surfaces such as a large area of grassy marshland, some desertification grassland areas, many small rivers and several lakes (Fig. 1).

The recent availability of high-resolution, multi-band imagery from the ASTER sensor has enabled us to estimate surface fluxes. ASTER covers a wide spectral region with 14 bands from the visible to the thermal infrared with high spatial, spectral and radiometric resolution. The spatial resolution varies with wavelength: $15 \mathrm{~m}$ in the visible and nearinfrared (VNIR, $0.52-0.86 \mu \mathrm{m}$ ), $30 \mathrm{~m}$ in the short wave infrared (SWIR, 1.6-2.43 $\mu \mathrm{m}$ ), and $90 \mathrm{~m}$ in the thermal infrared (TIR, 8.1-11.6 $\mu \mathrm{m}$ ) (Yamaguchi, 1998).

The most relevant data, collected at the CAMP/Tibet surface stations (sites) to support the parameterization of land surface heat fluxes and analysis of ASTER images in this paper, consist of surface radiation budget components, surface radiation temperature, surface albedo, vertical profiles of air temperature, humidity, wind speed and direction measured at the Atmospheric Boundary Layer (ABL) towers, Automatic Weather Stations (AWSs), radio sonde, turbulent fluxes measured by eddy correlation technique, soil heat flux, soil temperature profiles, soil moisture profiles, and the vegetation state.

\subsection{Theory and scheme}

The general concept of the methodology is shown in a diagram (Fig. 2). The surface albedo for shortwave radiation $\left(r_{0}\right)$ is retrieved from narrowband-broadband conversion by Liang (2001). ASTER has nine bands. It is expected that so many bands should enable us to convert narrowband to broadband albedos effectively. Liang found that the conversions are quite linear. The land surface temperature $\left(T_{\mathrm{sfc}}\right)$ is derived using a method developed by Hook (1992) from multispectral thermal infrared data. Hook (1992) also evaluated a technique to extract emissivity information from multispectral thermal infrared data. The techniques are the assumed Channel 5 emittance model (reference channel model). They permit emissivity information to be derived from all five ASTER channels. The assumed Channel 5 emittance model only permits emissivity values to be derived from four of the five ASTER channels (Hook, 1992). The radiative transfer model MODTRAN (Berk et al., 1989) computes the downward shortwave and longwave radiation at the surface. With these results the surface net radiation flux $\left(R_{n}\right)$ is determined. On the basis of the field observations, the soil heat flux $\left(G_{0}\right)$ 


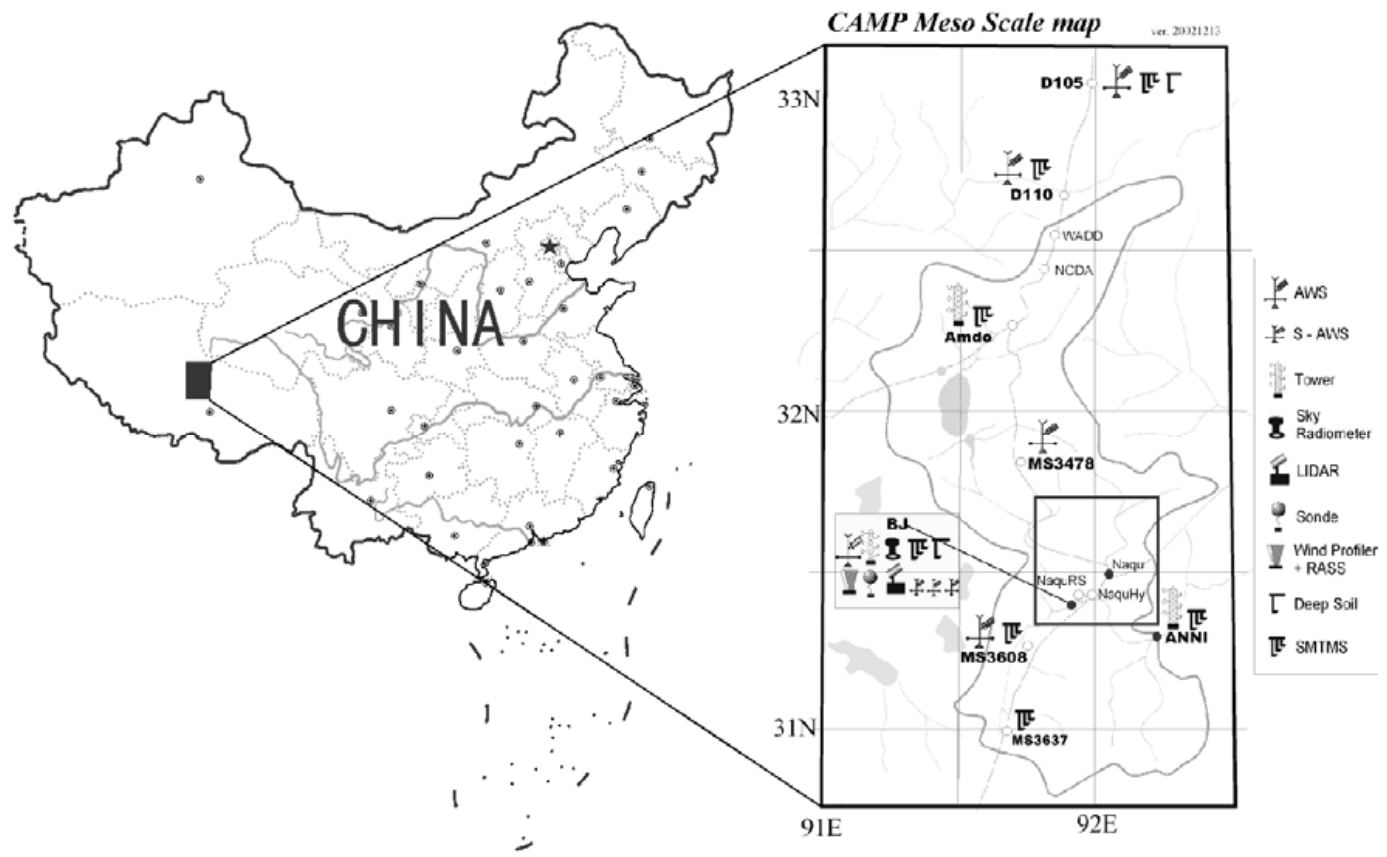

Fig. 1. Study area map and the sites during the CAMP/Tibet.

is estimated from $R_{n}$. The sensible heat flux $(H)$ is estimated from $T_{s f c}$, and regional latent heat flux $(\lambda E)$ is derived as the residual of the energy budget theorem (Liou, 2004; Ma, 2006) for land surface.

\subsubsection{Net radiation}

The regional net radiation flux is derived from

$$
\begin{aligned}
R_{n}(x, y)= & K_{\downarrow}(x, y)-K_{\uparrow}(x, y)+L_{\downarrow}(x, y)-L_{\uparrow}(x, y) \\
= & \left(1-r_{0}(x, y)\right) \cdot K_{\downarrow}(x, y)+L_{\downarrow}(x, y) \\
& -\varepsilon_{0}(x, y) \sigma T_{s f c}^{4}(x, y)
\end{aligned}
$$

where $\varepsilon_{0}(x, y)$ is surface emissivity, $K_{\downarrow}\left(\mathrm{W} \mathrm{m}^{-2}\right)$ represents the shortwave $(0.3-3 \mu \mathrm{m})$ and $L_{\downarrow}\left(\mathrm{W} \mathrm{m}^{-2}\right)$ is the longwave $(3-100 \mu \mathrm{m})$ radiation components, respectively. Surface albedo $r_{0}(\mathrm{x}, \mathrm{y})$ is derived from narrowband-broadband conversion method by Liang (2001). Since ASTER has nine bands, it is expected that so many bands should enable us to convert narrowband to broadband albedos effectively. Liang (2001) found that the conversions are quite linear. The resultant linear equations are collated in following.

$$
\begin{aligned}
r_{0}= & 0.484 \alpha_{1}+0.335 \alpha_{3}-0.324 \alpha_{5}+0.551 \alpha_{6}+0.305 \alpha_{8} \\
& -0.367 \alpha_{9}-0.0015
\end{aligned}
$$

where $\alpha_{i}(i=1-9)$ are the correspondent ASTER band surface reflectance.

The incoming shortwave radiation flux $K_{\downarrow}(\mathrm{x}, \mathrm{y})\left(\mathrm{W} \mathrm{m}^{-2}\right)$ in Eq. (1) is derived from radiative transfer model MODTRAN (Kenizys et al., 1996), The incoming long-wave radiation flux $L_{\downarrow}(\mathrm{x}, \mathrm{y})\left(\mathrm{W} \mathrm{m}^{-2}\right)$ in Eq. (1) is derived directly from MODTRAN (Ma and Tsukamoto, 2002; Ma et al., 2006). The model atmosphere used in MODTRAN is midlatitude summer with slant atmospheric path. The model of execution is thermal radiance. The other, such as temperature, pressure, wator vapor, ozone, methane, nitrous oxide, carbon monoxide, other gases, altitude profile, are set to midlatitude summer. Aerosols model used is rural VIS $=23 \mathrm{~km}$. Ground altitude above sea level is $4.5 \mathrm{~km}$. Surface temperature $T_{\text {sfc }}(\mathrm{x}, \mathrm{y})(\mathrm{K})$ in Eq. (1) is derived from ASTER thermal infrared spectral radiance (Hook, 1992).

\subsubsection{Soil heat flux}

The regional soil heat flux density $G_{0}(\mathrm{x}, \mathrm{y})\left(\mathrm{W} \mathrm{m}^{-2}\right)$ is determined through (Choudhury, 1988)

$G_{0}(x, y)=\rho_{s} C_{s}\left[\left(T_{s f c}(x, y)-T_{s}(x, y)\right] / r_{s h}(x, y)\right.$

where $\rho_{s}\left(\mathrm{~kg} \mathrm{~m}^{-3}\right)$ is soil dry bulk density, $C_{s}\left(\mathrm{~J} \mathrm{~kg}^{-1} \mathrm{~K}^{-1}\right)$ is soil specific heat, $T_{s}(\mathrm{x}, \mathrm{y})(\mathrm{K})$ represents soil temperature of a determined depth, and $r_{s h}(\mathrm{x}, \mathrm{y})\left(\mathrm{sm}^{-1}\right)$ stands for resistance of soil heat transportation. The regional soil heat flux $G_{0}(\mathrm{x}, \mathrm{y})\left(\mathrm{W} \mathrm{m}^{-2}\right)$ cannot directly be mapped from satellite observations through Eq. (3) because the difficulty to derive the soil heat transportation resistance $r_{s h}(\mathrm{x}, \mathrm{y})\left(\mathrm{sm}^{-1}\right)$ and the soil temperature at a determined depth $T_{s}(\mathrm{x}, \mathrm{y})(\mathrm{K})$ (e.g. Bastiaanssen, 1995; Ma et al., 2002b). Many investigations have shown that the midday $G_{0} / R n$ ratio, $\Gamma$, is reasonably predictable from special vegetation indices (Daughtry et al., 1990). $\Gamma$ is considered as a function $F$ which relates $G_{0} / R n$ to other variables (Ma and Tsukamoto, 2002). Some 


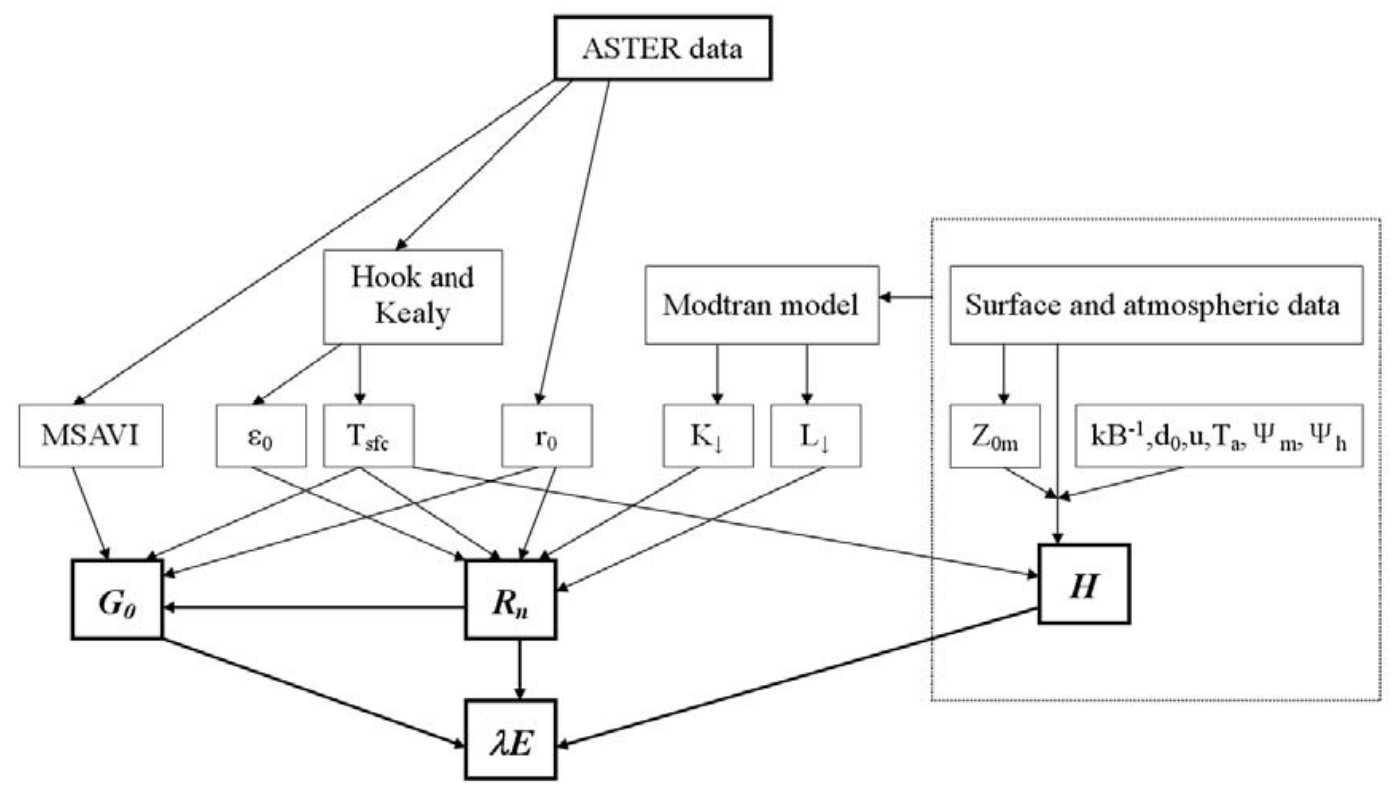

Fig. 2. Diagram of parameterization procedure by combining ASTER data with field observations.

researchers have concluded that $G_{0} / R n=\Gamma=F$ (NDVI) (Clothier et al., 1986; Kustas and Daughtry, 1990). A better ratio of $G_{0} / R n=\Gamma=F\left(r_{0}, T_{\mathrm{sfc}}\right.$, NDVI) was also found (Choudhury et al., 1987; Menenti et al., 1991; Bastiaanssen, 1995). The relationship between $G_{0}(x, y)\left(\mathrm{W} \mathrm{m}^{-2}\right)$ and $R_{n}(\mathrm{x}, \mathrm{y})$ $\left(\mathrm{W} \mathrm{m}^{-2}\right.$ ) found in the Tibetan Plateau area (Ma et al., 2003b) will be used to determine regional soil heat flux over the CAMP/Tibet area here. It means that $G_{0}(x, y)\left(\mathrm{W} \mathrm{m}^{-2}\right)$ is:

$$
\begin{aligned}
G_{0}(x, y)= & R_{n}(x, y) \cdot \frac{T_{\mathrm{sfc}}(x, y)}{r_{0}(x, y)} \cdot\left(0.00029+0.00454 \overline{r_{0}}\right. \\
& \left.+0.00878 \overline{r_{0}^{2}}\right) \cdot\left[1-0.964 \operatorname{MSAVI}(x, y)^{4}\right]
\end{aligned}
$$

Where $\overline{r_{0}}$ is the average albedo.

\subsubsection{Sensible heat flux}

The regional distribution of sensible heat flux is calculated from

$H(x, y)=\rho C_{p} \frac{T_{\mathrm{sfc}}(x, y)-T_{a}(x, y)}{r_{a}(x, y)}$

where aerodynamic resistance is

$$
\begin{aligned}
r_{a}(x, y)= & \frac{1}{k u_{*}(x, y)}\left[\ln \left(\frac{z-d_{0}(x, y)}{z_{0 m}(x, y)}\right)\right. \\
& \left.+k B^{-1}(x, y)-\psi_{h}(x, y)\right]
\end{aligned}
$$

where $\kappa$ is Von-Karman constant; $u_{*}\left(\mathrm{~ms}^{-1}\right)$ is friction velocity, $z(m)$ is reference height, $d_{0}(\mathrm{~m})$ is zero-plane displacement height, $z_{0 m}(\mathrm{~m})$ is the aerodynamic roughness, $k B^{-1}$ is the excess resistance for heat transportation, $\psi_{h}$ is the stability correction function for heat. The friction velocity $u_{*}$ is derived from

$u_{*}(x, y)=k u(x, y)\left[\ln \left(\frac{z-d_{0}(x, y)}{z_{0 m}(x, y)}\right)-\psi_{m}(x, y)\right]^{-1}$

where $\psi_{m}$ is the stability correction function for momentum.

From Eqs. (5-7)

$$
\begin{aligned}
& H(x, y)=\rho C_{p} \kappa^{2} u(x, y) \\
& \frac{\left[T_{s f c}(x, y)-T_{a}(x, y)\right]}{\left[\ln \frac{z-d_{0}(x, y)}{z_{0 m}(x, y)}+k B^{-1}-\psi_{h}(x, y)\right] \cdot\left[\ln \frac{z-d_{0}(x, y)}{z_{0 m}(x, y)}-\psi_{m}(x, y)\right]}
\end{aligned}
$$

where $z$ is the reference height and $u$ is the wind speed at the reference height. In the study, $z$ and $u$ are determined with the aid of field measurements of AWS (Automatic Weather Stations) system at the same height. $z_{0 m}(\mathrm{x}, \mathrm{y})$ in Eq. (8) over the Northern Tibetan area is calculated using Jia et al.'s model (Jia et al., 1999). $d_{0}$ is the zero-plane displacement, which is calculated using Stanhill's model (Stanhill, 1969). $T_{a}$ (x, y) in Eq. (8) is the regional distribution of air temperature at the reference height, it is derived from a linear method (Ma, 2007):

$$
T_{a}(x, y)=0.7784 T_{\mathrm{sfc}}(x, y)+60.1706
$$

Values of the excess resistance to heat transfer, $k B^{-1}$ versus $u\left(T_{\mathrm{sfc}}-T_{a}\right)$ over the Northern Tibetan Plateau is calculated in the following equation (Ma, 2006)

$k B^{-1}=0.062 u\left(T_{\mathrm{sfc}}-T_{a}\right)+0.599$ 

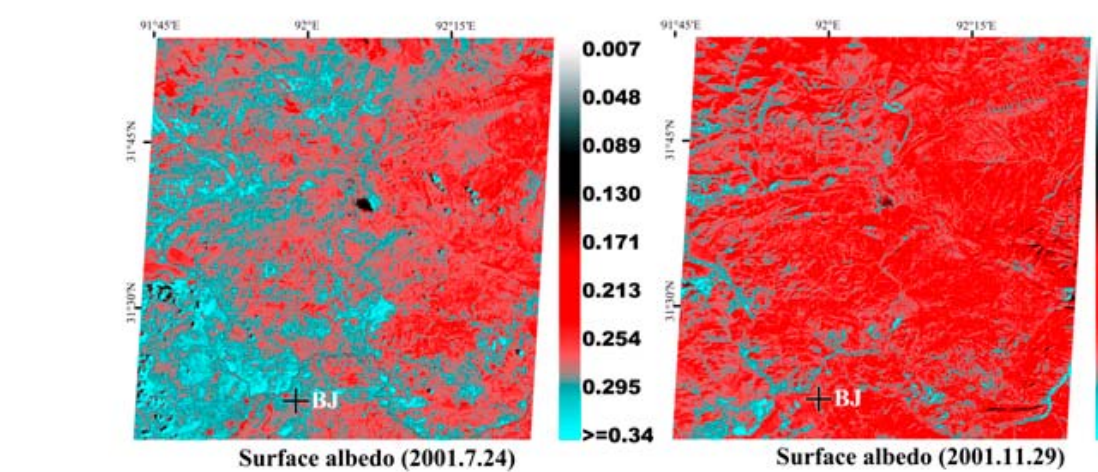

Surface albedo (2001.11.29)
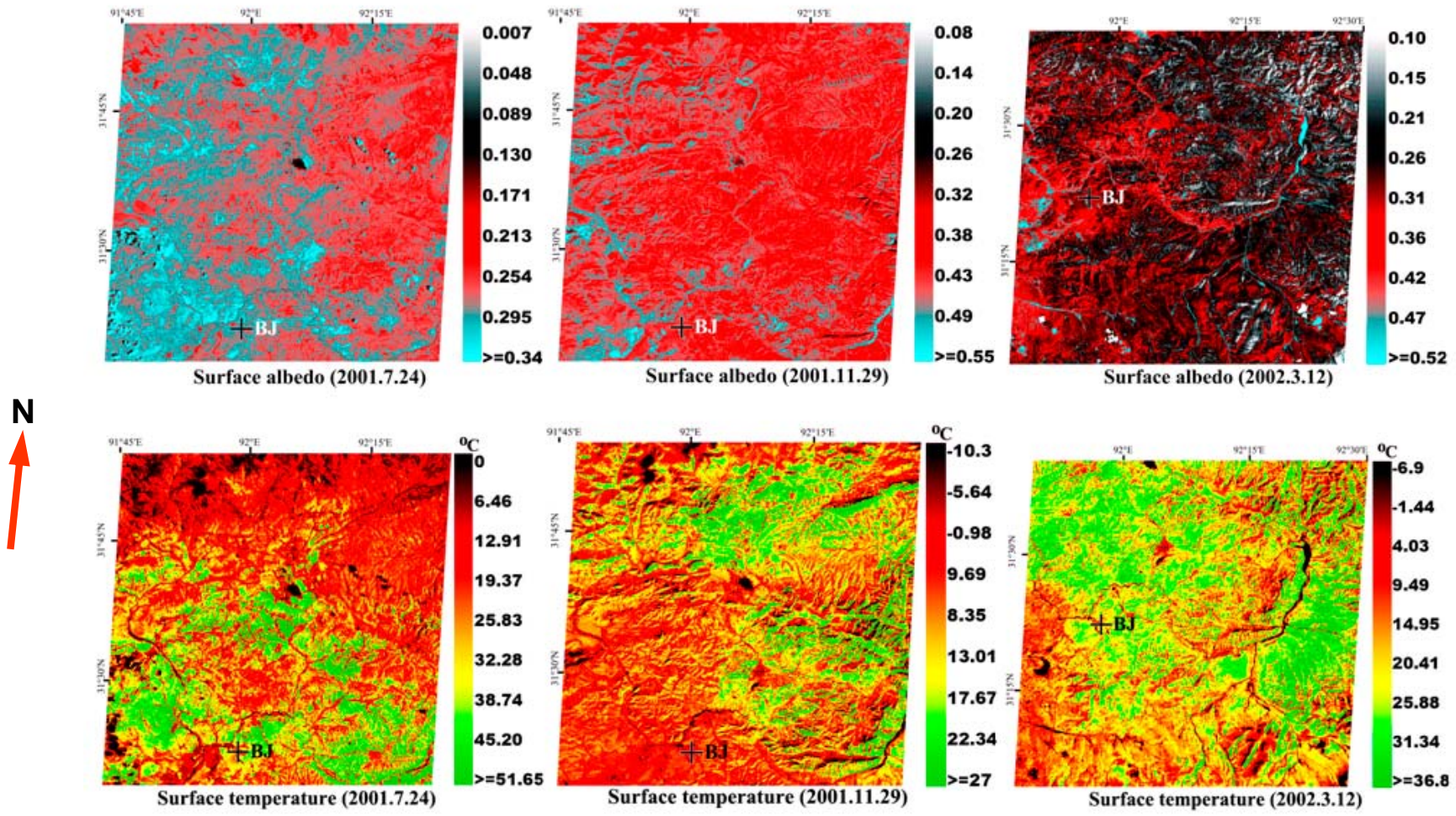

Fig. 3. Distribution maps of land surface variables over the CAMP/Tibet area.

$\psi_{h}(\mathrm{x}, \mathrm{y})$ and $\psi_{m}$ (x, y) in Eq. (8) are the integrated stability functions. For an unstable condition, the integrated stability functions $\psi_{h}(\mathrm{x}, \mathrm{y})$ and $\psi_{m}(\mathrm{x}, \mathrm{y})$ are written as (Paulson, 1970)

$\left\{\begin{array}{l}\psi_{m}(x, y)=2 \ln \left(\frac{1+X}{2}\right)+\ln \left(\frac{1+X^{2}}{2}\right)-2 \arctan (X)+0.5 \pi \\ \psi_{h}(x, y)=2 \ln \left(\frac{1+X^{2}}{2}\right)\end{array}\right.$

Where $X=\left\{1-16 \times\left[z-d_{0}(x, y)\right] / L(x, y)\right\}^{0.25}$. For a stable condition, the integrated stability function $\psi_{h}(\mathrm{x}, \mathrm{y})$ and $\psi_{m}$ (x, y) become (Webb, 1970)

$\psi_{m}(x, y)=\psi_{h}(x, y)=-5 \bullet \frac{z-d_{0}(x, y)}{L(x, y)}$

The stability function $\left[z-d_{0}(x, y)\right] / L(x, y)$ is calculated by Businger's method (Businger, 1988):

$\left\{\begin{array}{l}\frac{z-d_{0}(x, y)}{L(x, y)}=R_{i}(x, y) \quad \text { (unstable) } \\ \frac{z-d_{0}(x, y)}{L(x, y)}=R_{i}\left(x, y /\left[1-5.2 R_{i}(x, y)\right] \quad \text { (stable) }\right.\end{array}\right.$

where $R_{i}(\mathrm{x}, \mathrm{y})$ is the Richardson number; and according to the definition of the Richardson number, the approximate analytical solutions of $R_{i}$ found by Yang (2001) will be used here.

\subsubsection{Latent heat flux}

The regional latent heat flux $\lambda E(\mathrm{x}, \mathrm{y})\left(\mathrm{W} \mathrm{m}^{-2}\right)$ is derived as the residual of the energy budget theorem (Ma, 2006) for land
Table 1. The solar zenith angles information of 3 ASTER scenes.

\begin{tabular}{lcc}
\hline Date & $\begin{array}{c}\text { HH:MM:SS } \\
\text { (Beijing Time) }\end{array}$ & $\begin{array}{c}\text { solar zenith angle } \\
\text { (degree) }\end{array}$ \\
\hline 24 Jul 2001 & $12: 47: 59$ & 19.64792 \\
29 Nov 2001 & $12: 44: 03$ & 54.80759 \\
12 Mar 2002 & $12: 47: 25$ & 38.96375 \\
\hline
\end{tabular}

surface based on the condition of zero horizontal advection at $z<z_{\text {sur }}$, i.e.,

$\lambda E(x, y)=R_{n}(x, y)-H(x, y)-G_{0}(x, y)$

\section{Case studies and validation}

As a case study, 3 scenes of ASTER data over the Tibetan Plateau are used (see Table 1). Figure 3 shows the distribution maps of surface albedo and surface temperature around the CAMP/Tibet area. Their frequency distributions are shown in Fig. 4. Figure 5 shows the distribution maps of surface heat fluxes around the CAMP/Tibet area. Their frequency distributions are shown in Fig. 6. Figures 3 and 5 are based on $4980 \times 4200$ pixels of the ASTER data. The land surface variables (surface albedo and surface temperature) 

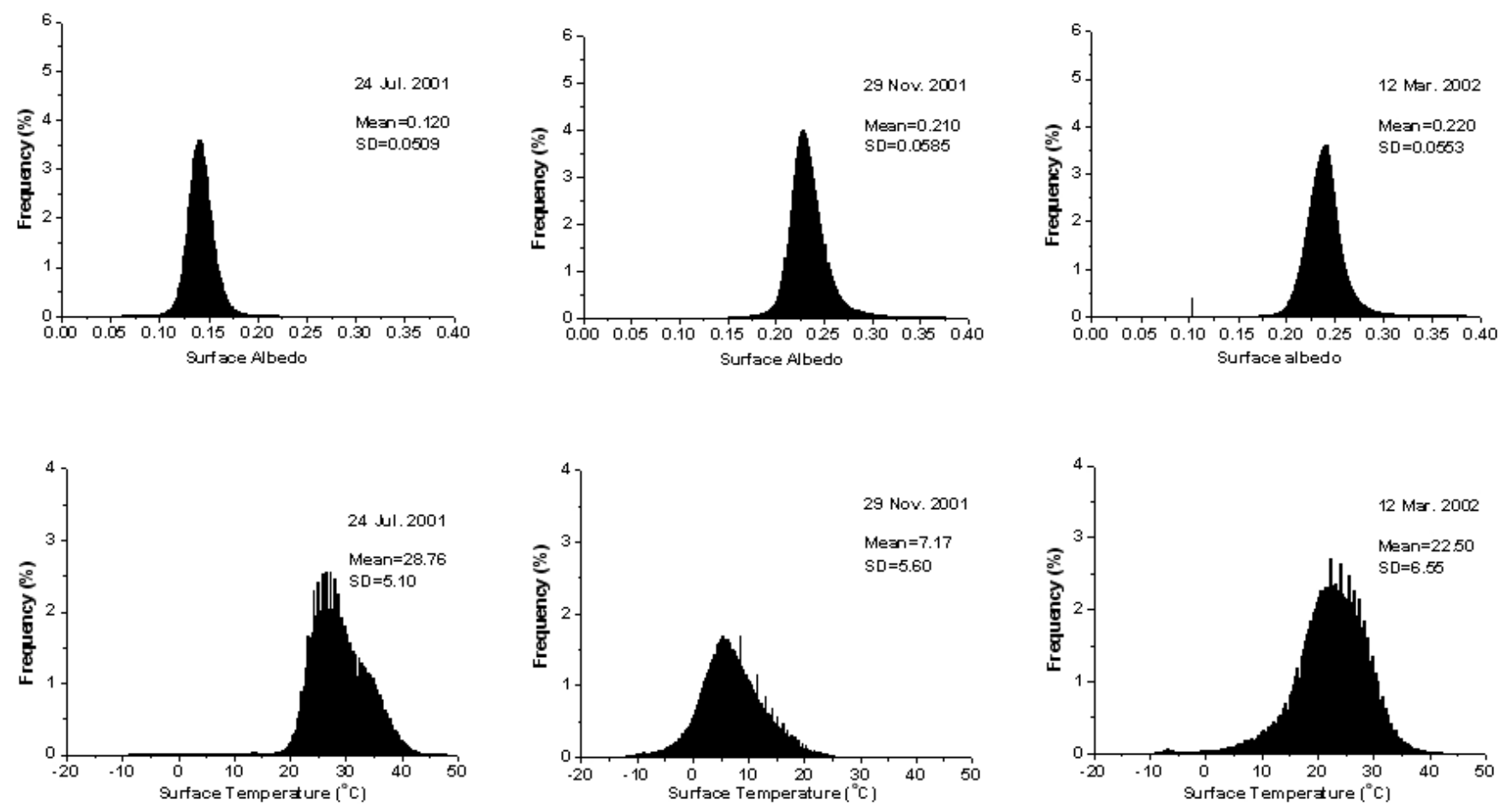

Fig. 4. Frequency distribution of surface albedo and surface temperature for the CAMP/Tibet area at 12:45 Beijing Time.

and land surface heat fluxes (net radiation flux, soil heat flux, sensible heat flux and latent heat flux) derived from satellite data were compared with the field measurements at BJ site (The BJ site is named after the nearby village BJ, which derived its name from the village chief who is called BUJIAO). The measured surface soil heat fluxes were calculated from soil heat flux measured at $-10 \mathrm{~cm}$ and the soil temperature measured at surface and $-10 \mathrm{~cm}$. The absolute percentage difference (APD) can quantitatively measure the difference between the derived results $\left(H_{\text {derived }(i)}\right)$ and measured values $\left(H_{\text {measured }(i)}\right)$ as

$\mathrm{APD}=\frac{\left|H_{\text {derived }(i)}-H_{\text {measured }(i)}\right|}{H_{\text {measured }(i)}}$

The results show the following:

1. The derived surface variables (land surface albedo and surface temperature) and surface heat fluxes (net radiation flux $R_{n}$, soil heat flux $G_{0}$, sensible heat flux $H$ and latent heat flux $\lambda E$ ) in three different months over the study area are in good accordance with the land surface status. The experimental area includes variety of land surfaces such as a large area of grassy marshland, some desertification grassland areas, many small rivers and several lakes; therefore these derived parameters show a wide range due to the strong contrast of surface features. Surface albedo is from 0.01 to 0.34 in July and from 0.08 to 0.55 in March and November. Surface temperature ranged from $0^{\circ} \mathrm{C}$ to $51.65^{\circ} \mathrm{C}$ in July and from $-10.3^{\circ} \mathrm{C}$ to $36.8^{\circ} \mathrm{C}$ in March and November. Net radiation flux changed from $570 \mathrm{~W} \mathrm{~m}^{-2}$ to $830 \mathrm{~W} \mathrm{~m}^{-2}$ in July and from $80 \mathrm{~W} \mathrm{~m}^{-2}$ to $655 \mathrm{~W} \mathrm{~m}^{-2}$ in March and November. Soil heat flux varied from $100 \mathrm{~W} \mathrm{~m}^{-2}$ to $220 \mathrm{~W} \mathrm{~m}^{-2}$ in July and from $0 \mathrm{~W} \mathrm{~m}^{-2}$ to $180 \mathrm{~W} \mathrm{~m}^{-2}$ in March and November. Sensible heat flux is from $0 \mathrm{~W} \mathrm{~m}^{-2}$ to $540 \mathrm{~W} \mathrm{~m}^{-2}$ in July and from $0 \mathrm{~W} \mathrm{~m}^{-2}$ to $520 \mathrm{~W} \mathrm{~m}^{-2}$ in March and November, and latent heat flux varied from $0 \mathrm{~W} \mathrm{~m}^{-2}$ to $736 \mathrm{~W} \mathrm{~m}^{-2}$ in July and $0 \mathrm{~W} \mathrm{~m}^{-2}$ to $288 \mathrm{~W} \mathrm{~m}^{-2}$ in March and November (see Figs. 3 and 5). Surface albedo, surface temperature and sensible heat flux around the lake in the distribution maps are much higher in July, and at the same time, net radiation flux, soil heat flux and latent heat flux are lower in the area. The reason is that the predominant land cover around the lake is composed by desertificated grass which was dry at the time of the measurement.

2. The derived pixel value (Figs. 3 and 5) and average value (see Figs. 4 and 6) of surface temperature, net radiation flux, soil heat flux and latent heat flux in July are higher than that in March and November. It means that there is much more evaporation in summer than in winter in the north Tibetan Plateau area. It is also pointed out that the heating density $\left(H+\lambda E=R n-G_{0}\right)$ in summer is much higher than that in winter in the central Tibetan Plateau area. This is caused by the high solar radiation and lower albedo in the summer and conversely the lower solar radiation and higher albedo in the winter. 


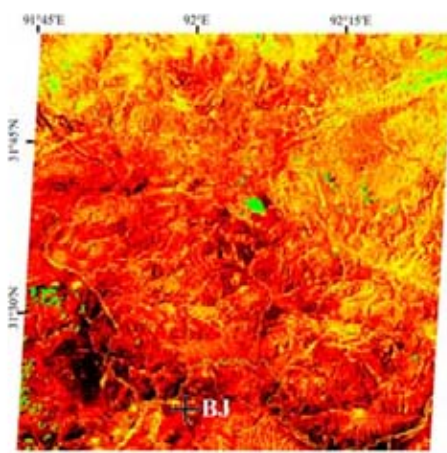

Net Radiation flux (2001.7.24)

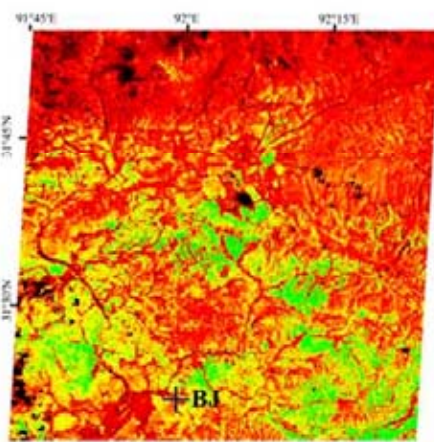

Soil heat flux (2001.7.24)

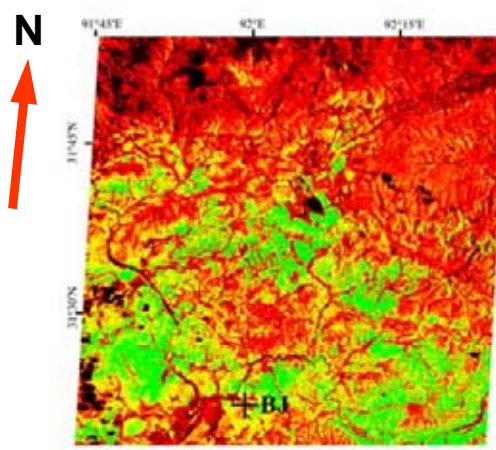

Sensible heat flux (2001.7.24)

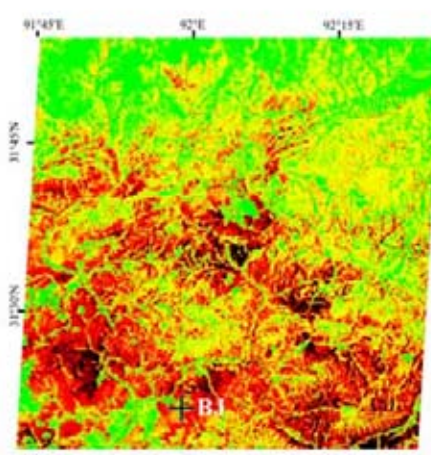

Latent heat flux (2001.7.24)

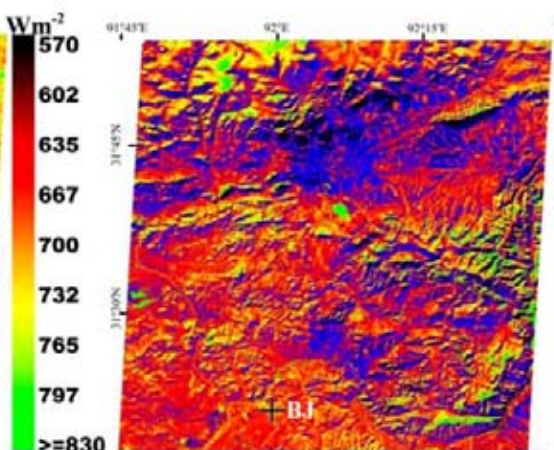

Net Radiation flux (2001.11.29)
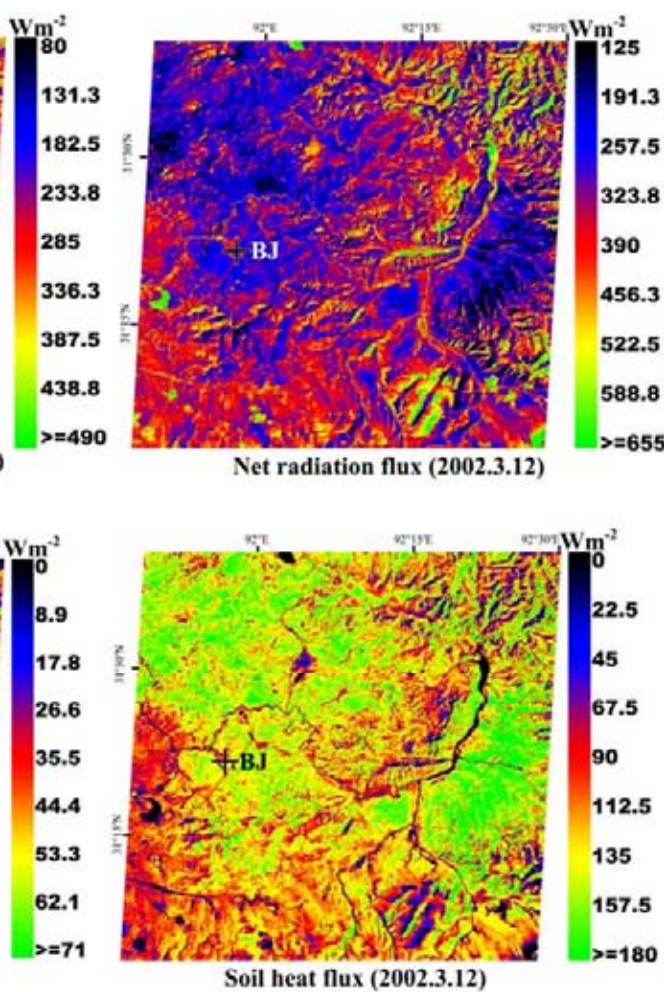

Soil heat flux (2001.11.29)

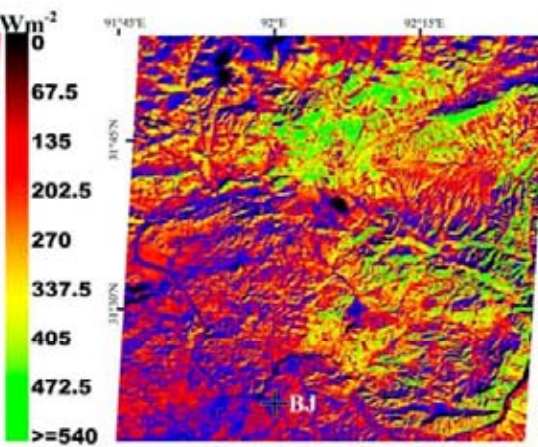

Sensible heat flux (2001.11.29)
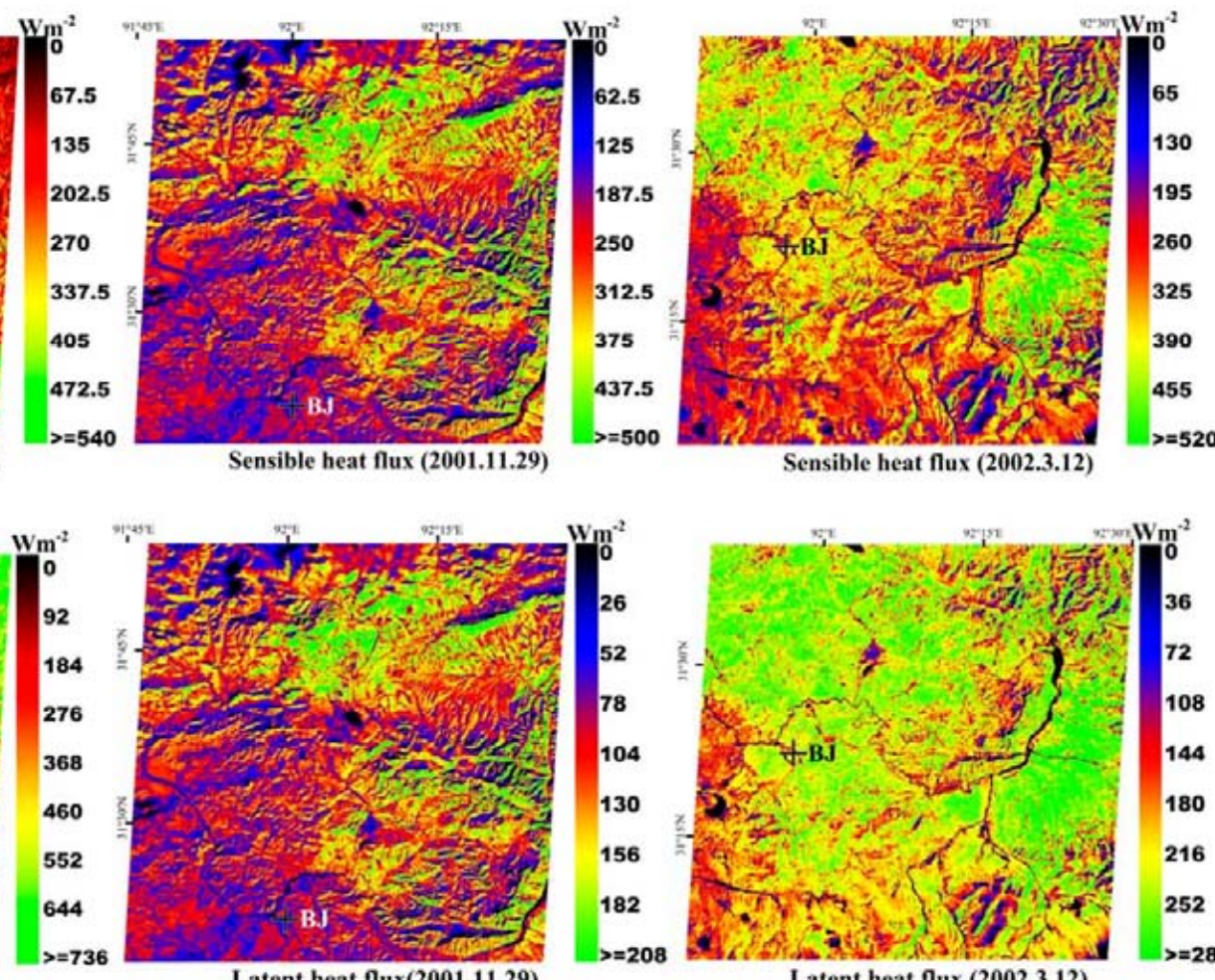

Latent heat flux(2001.11.29)
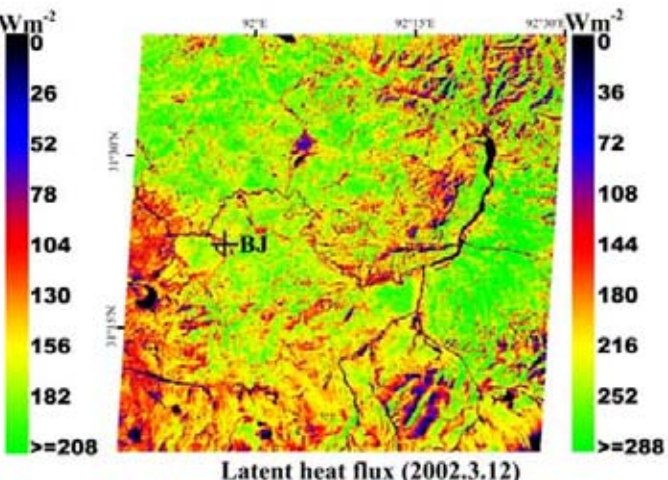

Fig. 5. Distribution maps of land surface heat fluxes over the CAMP/Tibet area. 

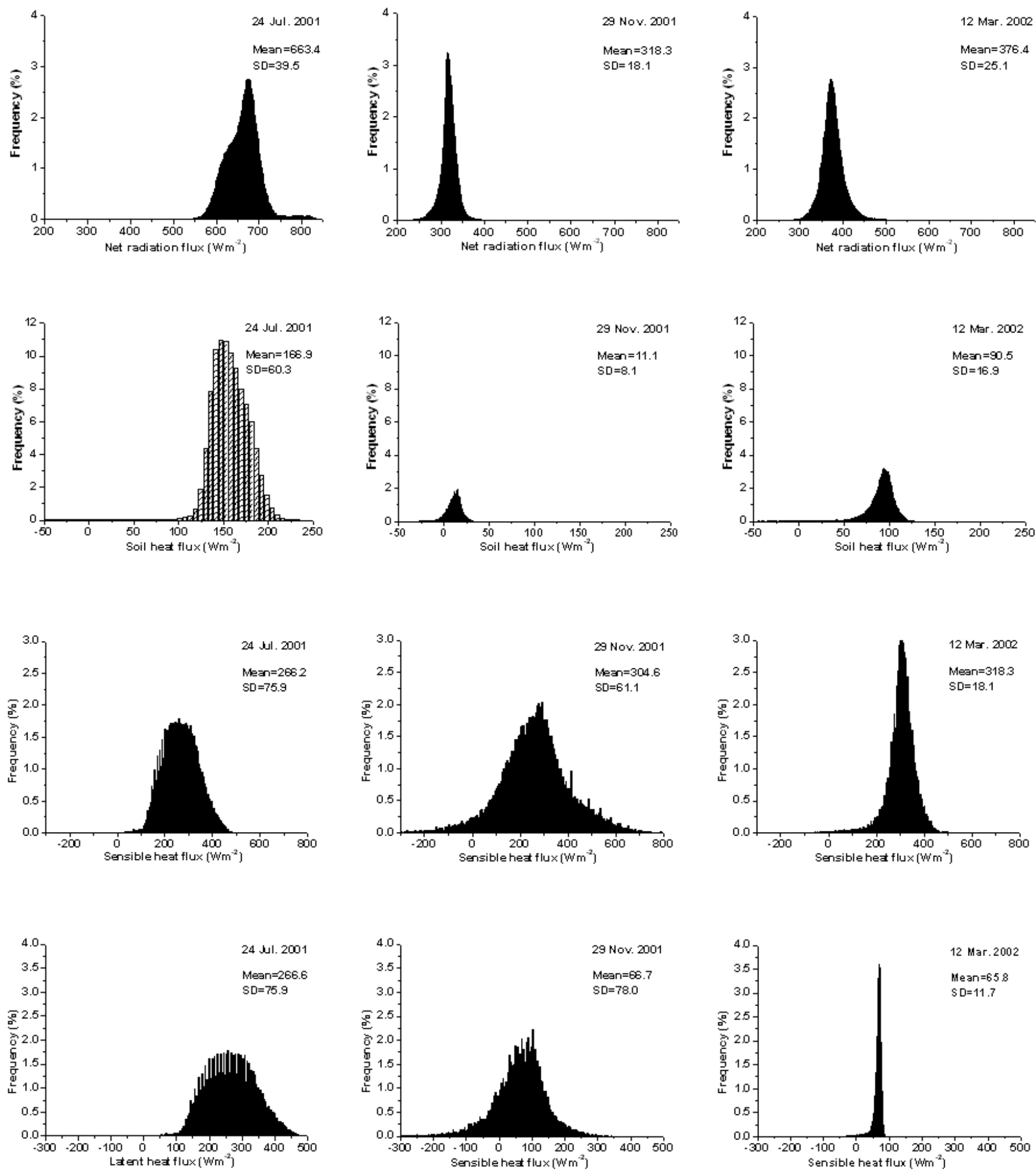

Fig. 6. Frequency distribution of land surface heat fluxes for the CAMP/Tibet area at 12:45 Beijing Time. 
Table 2. Comparison of the derived results (RS results) versus those measured values (observations) at the CAMP/Tibet site with APD.

\begin{tabular}{llcccc}
\hline Date & Items & $R n\left(\mathrm{~W} \mathrm{~m}^{-2}\right)$ & $H\left(\mathrm{~W} \mathrm{~m}^{-2}\right)$ & $G_{0}\left(\mathrm{~W} \mathrm{~m}^{-2}\right)$ & $\lambda E\left(\mathrm{~W} \mathrm{~m}^{-2}\right)$ \\
\hline \multirow{3}{*}{ 24 Jul 2001 } & Observations & 620.15 & 262.07 & 123.14 & 234.94 \\
& RS results & 637.03 & 268.24 & 133.16 & 243.60 \\
& APD & $2.6 \%$ & $2.3 \%$ & $7.5 \%$ & $3.6 \%$ \\
\hline \multirow{3}{*}{29 Nov 2001 } & Observations & 297.94 & 214.87 & 4.8 & 25.58 \\
& RS results & 307.40 & 201.22 & 4.69 & 27.20 \\
& APD & $3.1 \%$ & $6.8 \%$ & $2.1 \%$ & $6.0 \%$ \\
\hline \multirow{2}{*}{ 12 Mar 2002 } & Observations & 391.77 & 327.57 & 48.57 & 15.64 \\
& RS results & 387.64 & 350.74 & 53.74 & 17.35 \\
& APD & $1.0 \%$ & $6.6 \%$ & $9.6 \%$ & $9.8 \%$ \\
\hline
\end{tabular}

Most of the land surface is covered by green grass in summer and it is covered by snow and ice during winter on the experimental area.

3. The derived net radiation flux over the study area is very close to the field measurement with APD less than $3.1 \%$ (Table 2). It is the result of the improvement on surface albedo and surface temperature.

4. The regional soil heat flux derived from the relationship between soil heat flux and net radiation flux is suitable for heterogeneous land surface of the CAMP/Tibet area, and the APD is less than $9.8 \%$ at the validation sites (Table 2), because the relationship itself was derived from the same area (Ma et al., 2002b).

5. The derived regional sensible heat flux and latent heat flux with APD less than $9.8 \%$ at the validation sites in the CAMP/Tibet area is in good agreement with field measurements (Table 2). This is due to the fact that atmospheric boundary layer processes have been considered in more detail in our methodology and the proposed parameterization for sensible heat flux and latent heat flux can be used over the north Tibetan Plateau area.

\section{Concluding remarks}

In this study, the regional distributions of land surface variables (surface albedo and surface temperature) and land surface heat fluxes (net radiation flux, soil heat flux, sensible heat flux and latent heat flux) over the heterogeneous north Tibetan Plateau area were derived with the aid of ASTER data and field observations. Reasonable results of land surface variables, vegetation variables and land surface fluxes were gained in this study.

The retrieval of regional land surface heat fluxes over heterogeneous landscape is not an easy task. The parameteri- zation method presented in this study is still in developing stage:

1. Only three ASTER images are used in this study. To obtain more accurate regional land surface fluxes (daily to seasonal variations) over a larger area (the Tibetan Plateau), more field observations (ABL tower and radiation measurement system, radiosonde system, turbulent fluxes measured by eddy correlation technique, soil moisture and soil temperature measurement system etc.) and other satellite sensors such as MODIS (Moderate Resolution Imaging Spectroradiometer) and NOAA (National Oceanic and Atmospheric Administration)/AVHRR (Advanced Very High Resolution Radiometer) with more frequent temporal coverage have to be used. It is also worth trying SEBI (Surface Energy Balance Index (Menenti and Choudhury, 1993)) method and SEBS (Surface Energy Balance System (Su, 2002)).

2. This study implies the parameterization method is only applicable to clear-sky days (to apply MODTRAN and derive surface temperature). In order to extend its applicability to cloudy skies, we should consider using microwave remote sensing to derive surface temperature and other land surface variables.

Vegetation variables cannot be validated in this study because there were no such measurements during the field experiments. More attention should be paid to the measurements of vegetation variables in the coming experiments.

Acknowledgements. This work was under the auspices of the National Natural Science Foundation of China((40705004, 40825015 and 40810059006), Chinese National Key Programme for Developing Basic Sciences(2005CB422003), the Opening Foundation of Institute of Plateau Meteorology, CMA(LPM2007014), Opening Foundation of State Key Laboratory of Cryospheric Science (SKLCS 07-01) and The Key Projects of International Cooperation, Chinese Academy of Sciences(GJHZ0735). Special thanks are given to the anonymous reviewers and the editor for very constructive comments. The authors also thank all the participations from 
China, Japan and Korea for their very hard field work during the CAMP/Tibet.

Edited by: R. Ludwig

\section{References}

Baret, F. and Guyot, G.: Potentials and limits of vegetation indices for LAI and APAR assessment, Rem. Sens. Environ., 35, 161173, 1997.

Bastiaanssen, W. G. M.: Regionalization of Surface Flux Densities and Moisture Indicators in Composite Terrain, Ph.D. thesis, p. 143-161, Wageningen Agric. Univ., Wageningen, Netherlands, 1995.

Bastiaanssen W. G. M.: Regionalization of surface fluxes and moisture indicators in composite terrain, $\mathrm{PhD}$ Thesis, Wageningen Agricultural University, 273 pp., 1995.

Becker, F. and Li, Z.-L.: Towards a local split window method over land surfaces, Int. J. Remote Sens., 11, 369-393, 1990.

Becker, F. and Li, Z.-L.: Surface temperature and emissivity at various scales: Definition, measurement and related problems, Rem. Sens. Rev., 12, 225-253, 1995.

Berk, A., Bernstein, L. S., and Robertson, D. C.: MODTRAN: A moderate resolution model for LOTRAN-7, GL-TR-89-0122, Geophys. Lab., Hanscom Air Force Base, Mass., 1989.

Che'din, A., Scott, N. A., Wahiche, C., and Moulinier, P.: The improved initialisation inversion method: A high resolution physical method for temperature retrievals from Tiros-N series, J. Clim. Appl. Meteorol., 24, 124-143, 1985.

Choi, T., Hong, J., Kim, J., et al.: Turbulent exchange of heat, water vapor, and momentum over a Tibetan prairie by eddy covariance and flux variance measurements, J. Geophys. Res., 109, D21106, doi:10.1029/2004JD004767,2004.

Choudhury, B. J. and Monteith, J. L.: A four-layer model for the heat budget of homogeneous land surfaces, Q. J. Roy. Meteorol. Soc., 114, 373-398, 1988.

Choudhury, B. J., Idso, S. B., and Reginato, R. J.: Analysis of an empirical model for soil heat flux under a growing wheat crop for estimating evaporation by infrared-temperature based energy balance equation, Agric. For. Meteorol., 39, 283-297, 1987.

Clothier, B. E., Clawson, K. L., Pinter, P. J., Moran, M. S., Reginato, R. J., and Jackson, R. D.: Estimating of soil heat flux from net radiation during the growth of alfalfa, Agric. For. Meteorol., 37, 319-329, 1986.

Daughtry, C. S. T., Kustas, W. P., Moran, M. S., Pinter, P. J., Jackson, R. D., Brown, P. W., Nichols, W. D., and Gay, L. W.: Spectral estimates of net radiation and soil heat flux, Rem. Sens. Environ., 32, 111-124, 1990.

Hook, S. J., Gabell, A. R., Green, A. A., and Kealy, P. S.: A comparison of techniques for extracting emissivity information from thermal infrared data for geologic studies, Rem. Sens. Environ., 42, 123-135, 1992.

Jia, L., Menenti, M., and Wang, J.: Estimation of area roughness length for momentum using remote sensing data and measurements in field, Chinese J. Atmos. Sci., 23, 632-640, 1999 (in Chinese with English abstract).

Kahle, A. B. and Alley, R. E.: Separation of temperature and emittance in remotely sensed radiance measurements, Rem. Sens. Environ., 42, 107-112, 1992.
Kenizys, F. X., Abreu, L. W., Anderson, G. P., et al.: The MODTRAN3/2 report and LODTRAN 7 model, edited by: Abreu, L. W. and Andson, G. P., contract F19628-91-C-0132,Phillips Lab., Geophys. Dir., Hanscom Air Force Base, Mass., 1996.

Koepke, P., Kriebel, K. T., and Dietrich, B.: The effect of surface reflection and of atmospheric parameters on the short wave radiation budget, Adv. Space Res., 5, 353-354, 1985.

Kustas, W. P., Choudhury, B. J., Moran, M. S., Reginato, R. J., Jackson, R. D., Gay, L. W., and Weaver, H. L.: Determination of sensible heat flux over sparse canopy using thermal infrared data, Agric. For. Meteorol., 44, 197-216, 1989.

Kustas, W. P.: Estimates of evapotransiration with a one- and twolayer model of heat transfer over partial canopy cover, J. Appl. Meteorol., 29, 704-715, 1990.

Kustas, W. P. and Daughtry, C. S. T.: Estimation of the soil heat flux/net radiation ratio from spectral data, Agric. For. Meteorol., 39, 205-223, 1990.

Kustas, W. P. and Norman, J. M.: A two-source approach for estimating turbulent fluxes using multiple angle thermal infrared observations, Water Resour. Res., 33, 1495-1508, 1997.

Li, Z.-L. and Becker, F.: Feasibility of land surface temperature and emissivity determination from AVHRR data, Rem. Sens. Environ., 43, 67-85, 1993.

Liang, S.: Narrowband to broadband conversions of land surface albedo I Algorithms [J], Rem. Sens. Environ., 76, 213-238, 2000.

Liou, K. N.: An introduction to atmospheric radiation (Second Edition), China Meteorol. Press, Beijing, China, 2004.

Ma, W.: Estimating regional heat surface fluxes over heterogeneous landscapes of the Tibetan Plateau by using ASTER data, PhD Thesis, Chinese Academy of Sciences, 2007.

Ma, Y. and Tsukamoto, O.: Combining Satellite Remote Sensing With Field Observations for Land Surface Heat Fluxes Over Inhomogeneous Landscape, China Meteorol. Press, Beijing, China, 2002.

Ma, Y., Tsukamoto, O., Wang, J., Ishikawa, H., and Tamagawa, I.: Analysis of aerodynamic and thermodynamic parameters over the grassy marshland surface of Tibetan Plateau, Prog. Nat. Sci., 12, 36-40, 2002a.

Ma, Y., Su, Z., Li, Z.-L., Koike, T., and Menenti, M.: Determination of regional net radiation and soil heat flux densities over heterogeneous landscape of the Tibetan Plateau, Hydrol. Processes, 16(15), 2963-2971, 2002b.

Ma, Y., Su, Z., Koike, T., Yao, T., Ishikawa, H., Ueno, K., and Menenti, M.: On measuring and remote sensing surface energy partitioning over the Tibetan Plateau-From GAME/Tibet to CAMP/Tibet, Phys. Chem. Earth, 28, 63-74, 2003a.

Ma, Y., Ishikawa, H., Tsukamoto, O., Menenti, M., Su, Z., Yao, T., Koike, T., and Yasunari, T.: Regionalization of surface fluxes over heterogeneous landscape of the Tibetan Plateau by using satellite remote sensing, J. Meteorol. Soc. Jpn., 81, 277-293, $2003 b$.

Ma, Y., Fan, S., Ishikawa, H., Tsukamoto, O., Yao, T., Koike, T., Zuo, H., Hu, Z., and Su, Z.: Diurnal and inter-monthly variation of land surface heat fluxes over the central Tibetan Plateau area, Theor. Appl. Climatol., 80, 259-273, 2005.

Ma, Y., Zhong, L., Su, Z., Ishikawa, H., Menenti, M., and Koike, T.: Determination of regional distributions and seasonal variations of land surface heat fluxes from Landsat-7 Ehanced Thematic 
Mapper data over the central Tibetan Plateau area, J. Geophys. Res., 111, D10305, doi:10.1029/2005JD006742, 2006.

Ma, Y.: Determination of regional surface heat fluxes over heterogeneous landscapes by integrating satellite remote sensing with boundary layer observations, $\mathrm{PhD}$ Thesis, Wageningen University, 2006.

Menenti, M., Bastiaanssen, W. G. M., and Van Eick, D.: Determination of hemispheric albedo with Thematic Mapper data, Rem. Sens. Environ., 28, 327-337, 1989.

Menenti, M., Bastiaanssen, W. G. M., Hefny, K., and Abd EI Karim, M. H.: Mapping of ground water losses by evaporation in the Western Desert of Egypt, Rep. 43, p. 1-116, DLO Winand Staring Cent., Wageningen, Netherlands, 1991.

Menenti, M. and Choudhury, B. J.: Parameterization of land surface evaporation by means of location dependent potential evaporation and surface temperature range, in: Exchange Processes at the Land Surface for a Range of Space and Time Scales, edited by: Bolle, H. J., Feddes, R. A., and Kalma, J. D., IAHS Publ., 212, 561-568, 1993.

Norman, J. M., Kustas, W. P., and Humes, K. S.: A two-source approach for estimating soil and Vegetation energy fluxes from observations of directional radiometric surface temperature, Agric. For. Meteorol., 77, 263-293, 1995.

Paulson, C. A.: The mathematic representation of wind speed and temperature profiles in the unstable atmospheric surface layer, J. Appl. Meteorol., 9, 856-861, 1970.

Pinker, R. T.: Satellites and our understanding of the surface energy balance, Paleogr. Palaeoclimatol. Palaeoecol., 82, 321-342, 1990.

Price, J. C.: Estimating vegetation amount from visible and near infrared albedo, Rem. Sens. Environ., 41, 29-34, 1992.

Qi, J., Chehbouni, A., Huete, A. R., Kerr, Y. H., and Sorooshian, S.: A modified soil adjusted vegetation index, Rem. Sens. Environ., 48, 119-126, 1994.

Kato. S. and Yamaguchi, Y.: Analysis of urban heat-island effect using ASTER and ETM+ Data: Separation of anthropogenic heat discharge and natural heat radiation from sensible heat flux, Rem. Sens. Environ., 99, 44-54, 2005.

Schmugge, T. J., Hook, S., and Kahle, A.: TIMS observation of surface emissivity in HAPEX-Sahel, paper presented at International Geoscience and Remote Sensing Symposium, Inst. of Electr. and Electron. Eng., Florence, Italy, July, 1995.

Sellers, P. J., Rasool, S. I., and Bolle, H. J.: A review of satellite data algorithms for studies of the land surface, B. Am. Meteorol. Soc., 71, 1429-1447, 1990.

Shunlin Liang: Narrowband to broadband conversions of land surface albedo, Rem. Sens. Environ., 76, 213-238, 2001.

Sobrino, J. A. and Raissouni, N.: Toward remote sensing methods for land cover dynamic monitoring: application to Morocco, Int. J. Rem. Sens., 21(2), 353-366, 2000.

Stanhill, G.: A simple instrument for the ground measurement of turbulent diffusion flux, J. Appl. Meteorol., 8, 509-513, 1969.

Su, Z.: The Surface Energy Balance System (SEBS) for estimation of turbulent heat fluxes, Hydrol. Earth Syst. Sci., 6, 85-100, 2002, http://www.hydrol-earth-syst-sci.net/6/85/2002/.
Susskind, J., Rosenfield, J., Renter, D., and Chahine, M. T.: Remote sensing of weather and climate parameters from HIRS2/MSU on TIROS-N, J. Geophys. Res., 89, 4677-4697, 1984.

Tucker, C. J. (Ed.): Monitoring the grasslands of semi-arid Africa using NOAA AVHRR data, Int. J. Remote Sens., 7-11, 1383$1622,1986$.

Wan, Z. and Dozier, J.: Land surface temperature measurement from space: Physical principles and inverse modelling, IEEE Trans. Geosci. Remote Sens., 27, 268-278, 1989.

Wang, J., Ma, Y., Menenti, M., Bastiaanssen, W. G. M., and Mistsuta, Y.: The scaling-up of processes in the heterogeneous landscape of HEIFE with the aid of satellite remote sensing, J. Meteorol. Soc. Jpn., 73, 1235-1244, 1995.

Watson, K., Kruse, F., and Hummer-Miler, S.: Thermal infrared exploration in the Carlin trend, Geophysics, 55, 70-79, 1990.

Oku, Y. and Ishikawa, H.: Estimation of Land Surface Temperature over the Tibetan Plateau Using GMS Data, J. Appl. Meteorol., 43, 548-561, 2004.

Oku, Y., Ishikawa, H., and Su, Z.: Estimation of Land Surface Energy Fluxes over the Tibetan Plateau using GMS Data, J. Appl. Meteorol. Climatol., 46(2), 183-195, 2007.

Yamaguchi, Y., Kahle, A. B., Tsu, H., Kawakami, T., and Pniel, M.: Overview of the Advanced Spaceborne Thermal Emission and Reflection Radiometer (ASTER), Trans. Geosci. Remote Sens., 36(4), 1062-1071, 1998.

Yanai, M., Li, C., and Song, Z.: Seasonal heating of the Tibetan Plateau and its effects on the evolution of the Asian summer monsoon, J. Meteorol. Soc. Jpn., 70, 319-351, 1992.

Yang, K., Tamai, N., and Koike, T.: Analytical solution of surface layer similarity equations, J. Appl. Meteorol., 40, 1647-1653, 2001.

Yang, K., Koike, T., Fujii, H., Tamagawa, K., and Hirose, N.: Improvement of surface flux parameterizations with a turbulencerelated length, Q. J. Roy. Meteorol. Soc., 128B, 2073-2088, 2002.

Yang, K., Koike, T., and Yang, D.: Surface flux parameterization in the Tibetan Plateau, Bound. Lay. Meteorol., 116, 245-262, 2003.

Yang, K., Koike, T., Ishikawa, H., and Ma, Y.:, Analysis of the surface energy budget at a site of GAME/Tibet using a singlesource model, J. Meteorol. Soc. Jpn., 82, 131-153, 2004.

Ye, D. and Gao, Y.: The Meteorology of the Qinghai-Xizang (Tibet) Plateau, Sci. Press, Beijing, p. 1-278, 1979 (in Chinese).

Ye, D.: Some characteristics of the summer circulation over the Qinghai-Xizang (Tibet) Plateau and its neighborhood, B. Am. Meteorol. Soc, 62, 14-19, 1981.

Ye, D. and Wu, G.: The role of the heat source of the Tibetan Plateau in the general circulation, Meteorol. Atmos. Phys., 67, 181-198, 1998.

Zuo, H., Hu, Y., Li, D., Lu, S., and Ma, Y.: Seasonal transition and its boundary characteristics in Amdo area of Tibetan Plateau, Prog. Nat. Sci., 15, 239-245, 2005. 